\title{
Das Geheimnis der Gegenwart Gottes
}

\author{
Zur Schechina-Vorstellung in Judentum und Christentum \\ Hrsg. v. Bernd Janowski u. Enno Edzard Popkes unter Mitarb. v. Stefanie Hertel u. \\ Cordula Wiest
}

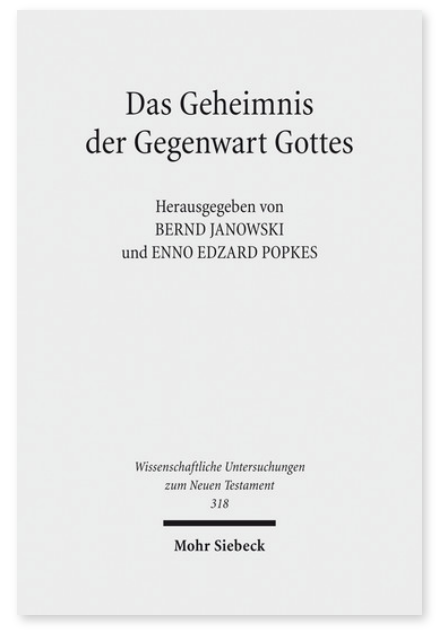

2014. VIII, 405 Seiten. WUNT I 318

ISBN 978-3-16-152992-4

DOI 10.1628/978-3-16-152992-4

eBook PDF 174,00€

ISBN 978-3-16-152991-7

Leinen $174,00 €$
In den biblischen Traditionen begegnen uns verschiedene Vorstellungen von der Gegenwart Gottes. Eine bedeutende Stellung nehmen in diesem Zusammenhang, Schechina-Vorstellungen' ein, die von der Einwohnung beziehungsweise dem Wohnen Gottes in einem Kultheiligtum oder einer menschlichen Gemeinschaft sprechen. An der Entwicklungsgeschichte der Schechina-Vorstellungen lässt sich ablesen, wie alttestamentlich-frühjüdische Traditionsbildungen fähig waren, religionsgeschichtliche Neuorientierungen beziehungsweise geschichtliche Ereignisse zu verarbeiten und traditionelle Glaubensvorstellungen zu modifizieren (vor allem in Folge der Zerstörung des ersten und zweiten Tempels). Auch eine Beschreibung der frühchristlichen Theologiegeschichte entbehrt wesentlicher Aspekte, wenn man die Aneignung dieses Erbes alttestamentlich-jüdischen Denkens nicht angemessen zur Geltung bringt. Gleichwohl erfahren Schechina-Vorstellungen in der biblisch-exegetischen Wissenschaft nur eine verhältnismäßig geringe Aufmerksamkeit. Der vorliegende Sammelband arbeitet die biblisch-theologischen Dimensionen der Schechina-Vorstellungen heraus und veranschaulicht ihr Potential für gegenwärtige Reflexionsprozesse christlicher und jüdischer Glaubensvorstellungen.

Inhaltsübersicht

Schechina-Vorstellungen im Judentum

Bernd Janowski: Die Einwohnung Gottes in Israel. Eine religions- und theologiegeschichtliche Skizze zur biblischen Schekina Theologie - Rüdiger Lux: Jerusalem - Stadt der Treue. JHWHs Schekina in Zion nach Sacharja 1-8 - Martin Leuenberger: Die personifizierte Weisheit als Erbin der atl. »Schechina« - Enno Edzard Popkes: Vorstellungen von der Einwohnung Gottes in der Tempelrolle: 11QT 29,7b-10 und die Entwicklungsgeschichte frühjüdischer Schechina-Vorstellungen - Jutta LeonhardtBalzer: Vorstellungen von der Gegenwart Gottes bei Philo von Alexandrien - Peter Schäfer: „Denn ich will unter ihnen wohnen«: Die Schechina der Rabbinen - Elke Morlok: Erotische Anziehung und doppelte Konstruktion der Schechina in der kabbalistischen Literatur - Matthias Morgenstern: Die Schechina zwischen Halacha und Aggada. Versuch über ein Gedicht Ch.N. Bialiks im Gespräch mit Gershom Scholem

Schechina-Vorstellungen im Christentum

David du Toit: Motive der Gottesgegenwart in der Synoptischen Tradition - Samue/ Vollenweider: Göttliche Einwohnung. Die Schechina-Motivik in der paulinischen Theologie - Hermann Lichtenberger: Das Motiv der Einwohnung in der Ekklesiologie des Epheserbriefs - Jörg Frey: Joh 1,14, die Fleischwerdung des Logos und die Einwohnung Gottes in Jesus Christus. Zur Bedeutung der Schechina- Theologie für die johanneische Christologie - Franz Tóth: Die Schechina-Theologie in der Johannesapokalypse - Tobias Nicklas: Altkirchliche Diskurse um das »Wohnen Gottes«. Eine Spurensuche bis zur Zeit der Konstantinischen Wende - Vasile Hristea: Einwohnung der Herrlichkeit. Gregors von Nyssa Auffassung der Gegenwart Gottes im Menschen - Paul Silas Peterson: Schechina-Vorstellungen in der Bibelauslegung des 17. und 18. Jahrhunderts in England und in den britischen Kolonien in Nordamerika

Bernd Janowski Geboren 1943; Studium der Theologie, Ägyptologie und Assyriologie in Tübingen; 1980 Promotion; 1984 Habilitation; nach Professuren in Hamburg (1986-91) und Heidelberg (1991-95) seit 1995 Professor für Theologie des Alten Testaments in Tübingen; seit 1995 Mitglied der Heidelberger Akademie der Wissenschaften; seit 2011 emeritiert.

Enno Edzard Popkes Geboren 1969; Studium der Theologie und Philosophie; 2004 Promotion; 2007 Habilitation; seit 2010 Professor für Geschichte und Archäologie des frühen Christentums und seiner Umwelt am Institut für Neues Testament und Judaistik an der Theologischen Fakultät der Christian-Albrechts-Universität zu Kiel.

Stefanie Hertel Keine aktuellen Daten verfügbar.

Cordula Wiest Keine aktuellen Daten verfügbar.

Jetzt bestellen:

https://mohrsiebeck.com/buch/das-geheimnis-der-gegenwart-gottes-9783161529924?no_cache=1

order@mohrsiebeck.com

Telefon: +49 (0)7071-923-17

Telefax: $+49(0) 7071-51104$ 